www.jmscr.igmpublication.org

Impact Factor 5.84

Index Copernicus Value: 71.58

ISSN (e)-2347-176x ISSN (p) 2455-0450

crossref DOI: _https://dx.doi.org/10.18535/jmscr/v5i11.120

Journal Of Medical Science And Clinical Research

IGM Publication

An Official Publication of IGM Publication

\title{
Efficacy of Myofascial Release Technique in Comparison with Passive Stretching in Reducing Spasticity in children with Cerebral Palsy*
}

\author{
Authors \\ Ujwal Bhattacharya ${ }^{1}$, Dr Nirmal Chandra Bhattacharyya ${ }^{2}$, Urvashi Bhattacharya ${ }^{3}$ \\ ${ }^{1} \mathrm{PhD}$ Scholar, Srimanta Sankaradeva University of Health Sciences, Guwahati \\ Email: ujwalbhatta@gmail.com \\ ${ }^{2}$ Retired Professor cum Head, Department of Paediatric Surgery, Gauhati Medical College and Hospital \\ Email: nirmalbhattacharya1951@gmail.com \\ ${ }^{3}$ Assistant Professor, Dept of Physiotherapy, University of science and technology Meghayalaya, Roi bhoi \\ Email: urvashibhatta@gmail.com
}

*A part of the ongoing PhD work under Srimanta Sankaradeva University of Health Sciences, Assam

\begin{abstract}
Background: Spasticity is a common pathological manifestation seen in children with Cerebral palsy. Ankle impairments are closely associated with functional limitations in children with cerebral palsy (CP). As a pattern of tradition spasticity is conservatively managed by application of manual stretching to elongate the tight musculoskeletal structures. But studies suggest that due to stretching there is activation of excitatory impulses which in turn may increase the tone of muscles So this study is done to establish the efficacy of myofascial release technique in comparison to passive stretching.

Objective: To determine whether Myofascial release technique effective in the treatment of spasticity in children with cerebral palsy in comparison to passive stretching.

Methods: Data of 94 children's with Cerebral palsy (Boys-61, Girls-33) with mean age 7 years were included in the study. The subjects were divided into Control and Interventional group. Control group received Passive stretching technique while Interventional group received Myofascial release techniqueat a rate of 6 days per week for 12 weeks consecutively. The outcome was measured using GMFM score, MAS score and GONIOMETRY.

Results: The data was analysed using SPSS 15.0 version. ANOVA test was performed and found significant differences between treatment by Myofascial release techniqueand Passive stretching technique with $p$ value <.001. Cochran Mantel Haenszel tests when stratified by the methods in the present study found significant association indicating the likelihood of Passive stretching technique being superior to Myofascial release technique ( Chi sq-9.55, $d f=1, p=0.002$ ).

Conclusion: Both the techniques i.e., Passive stretching technique as well as Myofascial release technique were found to be having significant effects. While on the basis of outcomes of GMFM grade, MAS grade and ROM (Dorsiflexion), Passive stretching was found to be more effective then Myofascial release.
\end{abstract}

Keywords: Cerebral palsy, Myofascial release, Passive stretching.

\section{Introduction}

Cerebral Palsy (CP) is a collection of motor disorders resulting from damage to the brain that occurs before, during or after birth. The damage to the child's brain affects the motor system, and as a result the child has poor coordination, poor 
balance or abnormal movement patterns- or a combination of these characteristics. ${ }^{(1)}$

The universally recognized definition of cerebral palsy is "a non progressive but not unchanging disorder of movement and/or posture due to an insult to or anomaly of the developing nervous system". CP is a static disorder of the brain, not a progressive disorder. This means that the disorder or the disease process will not get worse as the time goes on. ${ }^{(1)}$

Spasticity is one of the most common manifestations exhibited by children with Cerebral palsy. The development of this velocity dependent increase in tone of the muscle is seen mainly in the antigravity muscles of the lower limbs. Amongst all the lower limb muscles, the plantar flexors are most frequently effected.$^{(2)}$ This leads to difficulty in ambulation by the child. As a method of tradition passive stretching is commonly included in the treatment protocol of a children with Cerebral palsy including other conventional therapy techniques. ${ }^{(3,4)}$

Myofascial release is a manual energetic therapy designed to treat the myofascia that surrounds every cell and tissues in the body. Myofascial release is a highly interactive stretching technique that requires feedback from the patient's body to determine the direction, force $\&$ duration of the stretch \& to facilitate maximum relaxation of tight or restricted tissues. Myofascial Release recognizes that a muscle cannot be isolated from other structures of the body \& is connected to all other structures by fascia. Fascia covers all the internal organs of the body, including entire muscles \& the individual myofibrils that compose each muscle. ${ }^{(5)}$

When using Myofascial Release techniques, the therapist develops a kinesthetic link with the patient through touch. This link allows the therapist to monitor the patient's inherent tissue motion \& underlying neurophysiologic tissue tone as well as the more overt muscle tone. Only through touch can the therapist detect not only gross but also subtle tightness \& restrictions to efficient movement within individual muscles \& myofascial units. ${ }^{(5)}$ These subtle areas of tightness or restriction can only be detected through touch $\&$ treated successfully using Myofascial Release techniques.

This study was conducted to find whether Myofascial release technique which is a manual therapy technique is effective in the treatment of spasticity of Plantar flexors in childrens with Cerebral palsy.

\section{Materials and Methods}

The subjects were gathered from two eminent organisations of Assam which receive maximum number of cerebral palsy cases Physical medicine and rehabilitation department, $\mathrm{GMCH}$, Guwahati; and Composite rehabilitation center, $\mathrm{GMCH}$ campus, Guwahati. The study included 95 children with cerebral palsy. The subjects were diagnosed Spastic children with Cerebral palsy within the age group of 12 months to 12 years. All the subjects were divided into a control group and a interventional group. The control group received only the conventional treatment including passive stretching and the interventional group received Myofascial release technique. To check the prognosis the Ambulation, Muscle tone and Ankle range of motion (dorsiflexion) is measured using gross motor functional measure GMFM ,Modified Ashworth scale (MAS) and goniometry Inclusion Criteria

- Age group - 12 months to 12 years

- Children within the geographical distribution of Kamrup district.

- Diagnosed Spastic children with Cerebral palsy

- Spastic diplegic

- Spastic monoplegic

- Spastic hemiplegic

\section{Exclusion Criteria}

- Athetoid cerebral palsy

- Dyskinetic cerebral palsy

- Ataxic cerebral palsy

- Hypotonic cerebral palsy

- Childs with visual or auditory deficit

- Children's with cognitive dysfunction 
- Mentally retarded child's

The study included 95childrens with Cerebral palsy with spasticity taken in a randomized sampling manner. Subjects of both the gender are taken for the study who were obtained from the organizations as mentioned. The informed consent was obtained from the parents of the subjects included for the study. Rationale behind the techniques of administration and the benefits was made clear to the parents of the subjects. The subjects were divided into 2 groups consisting of Conventional techniques and interventional group. $\mathrm{Gr}$ - I was administered with conventional treatment and $\mathrm{Gr}$-II was administered with Myofascial release techniques. The technique was administered at a rate of 5 repetition for each muscle group or joint with a hold of $20-60 \mathrm{sec}$. Each group received treatment at the rate of 6 days a week for a period of 12 weeks. The pre treatment and post treatment clinical parameters are documented in an assessment sheet. The clinical parameters are: muscle tone and range of motion.

Outcome measures viz. GMFM, ROM (DF) on 41 subjects with Myofascial release and 54 subjects in Passive stretching were repeatedly followed up in pre and post occasions, for analysing efficacy of interventions of two methods. Repeated Measure Design at pre and post intervention occasions was done.
Model : Subject effect + Method effect + Subject $\times$ Method effect (Error I) + Time + Timex Method interaction effect+ Error(II)

[Justification :-Split Unit Design ( ref: i.e. Split Time Design , Armitage and Berry 1994 p. 265, p.432, Pp. 430-43] $]^{(6,7)}$

Post hoc test were done if and only if effect was significant. For all pairs, the same was done by Tukey HSD test (Tukey ; 1953). ${ }^{(8)}$ Further the same subjects in respective Myofascial release and Passive stretching repeated follow-up were subjected to analysing efficacy of interventions of two methods with respect to MAS by chi square test.

Data Analysis Methods and software: SPSS 15.0; SPSS Inc. Chicago, USA and SAS 9.3, SAS Inc. Cary, NC, USA

\section{Results}

The ANOVA (Table 1) found significant differences in MFR and PS methods $(P<001)$. Also it established pre post test measure in GMFM $(P<001)$ and ROM (DF; $(P<001)$ indicating significance of intervention. However, method $x$ test interaction was insignificant $(P=.819)$ indicating that methods did not significantly vary with respect to pre and post measure.

Table 1: ANOVA -Tests on Dependent Variables: GMFM and ROM(DF)

\begin{tabular}{|c|c|c|c|c|c|c|c|}
\hline \multirow[b]{2}{*}{ Source } & \multirow[b]{2}{*}{ df } & \multicolumn{3}{|c|}{ GMFM } & \multicolumn{3}{|c|}{ ROM(DF) } \\
\hline & & $\begin{array}{c}\text { Mean } \\
\text { Square }\end{array}$ & $\mathrm{F}$ & $P$-value & \begin{tabular}{|c|} 
Mean \\
Square
\end{tabular} & $\mathrm{F}$ & $P$-value \\
\hline Subject & 53 & 24.15 & & & 13.68 & & \\
\hline Method (MFR vs PS) & 1 & 123.99 & 132.34 & $<.001 * *$ & 193.20 & 86.44 & $<.001 * *$ \\
\hline Subject $\times$ Method & 40 & 25.94 & & & 17.38 & & \\
\hline Test (pre post) & 1 & 38.22 & 40.79 & $<.001 * *$ & 469.00 & 209.84 & $<.001 * *$ \\
\hline Method $\times$ Test & 1 & 1.08 & 1.15 & $.287^{\mathrm{NS}}$ & 0.12 & 0.05 & $.819^{\mathrm{NS}}$ \\
\hline Error & 93 & 0.94 & & & 2.24 & & \\
\hline & & \multicolumn{3}{|c|}{$\mathrm{R}^{2}=.966\left(\right.$ Adjusted $\left.\mathrm{R}^{2}=.931\right)$} & \multicolumn{3}{|c|}{$\mathrm{R}^{2}=.913\left(\right.$ Adjusted $\left.\mathrm{R}^{2}=.823\right)$} \\
\hline
\end{tabular}

Mean \pm SE analysis (Table 2) established that average pre GMFM(51.56 \pm 0.63$)$ in case of MFR increased by $0.75 \pm 0.20$ (95\% CI: $0.34-1.17$ ) while the same in case of Passive Stretch, pre GMFM
$(52.99 \pm 0.49)$ improved by $1.06 \pm 0.19 \quad(95 \%$ CI:0.67-1.44) indicating significant differences in Myofascial release technique and Passive Stretching methods $(\mathrm{P}<001)$. ROM(DF) analysis 


\section{JMSCR Vol||05||Issue||11||Page 30515-30520||November}

also established that pre ROM-DF(12.07 \pm 0.49$)$ in case of MFR increased by $3.12 \pm 0.35$ (95\% CI: 2.42-3.82) while the same in case of Passive Stretching pre $\mathrm{ROM}(\mathrm{DF})$ i.e. $9.59 \pm 0.36$ increased by $3.22 \pm 0.28$ (95\% CI: 2.67-3.78). With respect to ROM(DF) also the study accounted significant differences in Myofascial release technique and Passive Stretching methods $(\mathrm{P}<001)$.

Table 2: Mean \pm SE of GMFM and ROM(DF) with pre post Differentials in MFR and PS

\begin{tabular}{|c|c|c|c|c|}
\hline Method & Parameter & Mean \pm SE & $\begin{array}{c}\text { Mean } \\
\text { Difference } \\
\pm \text { SED }\end{array}$ & $\begin{array}{l}95 \% \mathrm{CI} \text { of } \\
\text { the Difference }\end{array}$ \\
\hline \multirow{4}{*}{$\begin{array}{l}\text { Myofascial } \\
\text { release } \\
\text { technique } \\
(\mathrm{n}=41)\end{array}$} & GMFM PRE & $51.56 \pm 0.63$ & \multirow{2}{*}{$0.75 \pm 0.20$} & \multirow{2}{*}{$0.34-1.17$} \\
\hline & GMFM POST & $52.31 \pm 0.58$ & & \\
\hline & ROM(DF) PRE & $12.07 \pm 0.49$ & \multirow{2}{*}{$3.12 \pm 0.35$} & \multirow{2}{*}{$2.42-3.82$} \\
\hline & ROM(DF) POST & $15.20 \pm 0.51$ & & \\
\hline \multirow{4}{*}{$\begin{array}{l}\text { Passive } \\
\text { Stretching } \\
(\mathrm{n}=54)\end{array}$} & GMFM PRE & $52.99 \pm 0.49$ & \multirow{2}{*}{$1.06 \pm 0.19$} & \multirow{2}{*}{$0.67-1.44$} \\
\hline & GMFM POST & $54.05 \pm 0.42$ & & \\
\hline & ROM(DF) PRE & $9.59 \pm 36$ & \multirow{2}{*}{$3.22 \pm 0.28$} & \multirow{2}{*}{$2.67-3.78$} \\
\hline & ROM(DF) POST & $12.81 \pm 0.38$ & & \\
\hline
\end{tabular}

Analysis of MAS2+(Table 3 and Fig. 1)found that in case of PS, number of subjects reduced by $100 \%$ while MAS 2 in case of MFR, it reduced by $72.7 \%$. Similarly, in case of MAS 1+, it reduced by $14.8 \%$ in case of MFR and $8.0 \%$ in PS. However, there was increase by $400.0 \%$ in MFR and $10.7 \%$ in PS. It found significant differences in pre post intervention and MAS association of MFR $(P=.002)$ but insignificant association in PS $(P=.539)$. Cochran-Mantel-Haenszel Tests when stratified by method found significant association (Chi sq=9.55, $\mathrm{df}=1, P=.002)$ indicating likelihood that of PS was superior.

Table 3: Count Analysis in Pre and Post MAS Differentials in MFR and PS

\begin{tabular}{|c|c|c|c|c|c|c|}
\hline \multirow[b]{2}{*}{ MAS } & \multicolumn{3}{|c|}{ MFR } & \multicolumn{3}{|c|}{ PS } \\
\hline & Pre & Post & $\begin{array}{l}\text { Decrease }(+) / \\
\text { increase }(-) \%\end{array}$ & Pre & Post & $\begin{array}{l}\text { Decrease }(+) / \\
\text { increase }(-) \%\end{array}$ \\
\hline 1 & 3 & 15 & $-400.0 \%$ & 28 & 31 & $-10.7 \%$ \\
\hline $1+$ & 27 & 23 & $14.8 \%$ & 25 & 23 & $8.0 \%$ \\
\hline 2 & 11 & 3 & $72.7 \%$ & - & - & - \\
\hline $2+$ & - & - & - & 1 & 0 & $100.0 \%$ \\
\hline \multirow[t]{2}{*}{ Total } & 41 & 41 & & 54 & 54 & \\
\hline & \multicolumn{3}{|c|}{ Chi $\mathrm{Sq}=12.89, \mathrm{df}=2, P=.002 * *$} & \multicolumn{3}{|c|}{ Chi $\mathrm{Sq}=1.24, \mathrm{df}=2, P=.539^{\mathrm{NS}}$} \\
\hline
\end{tabular}

** Significant at $P(<.01) ;{ }^{\text {NS }}$ Not Significant at $P(>.05)$

Fig. 1 Average Chart showing Pre Post GMFM and ROM-DF in MFR and PS
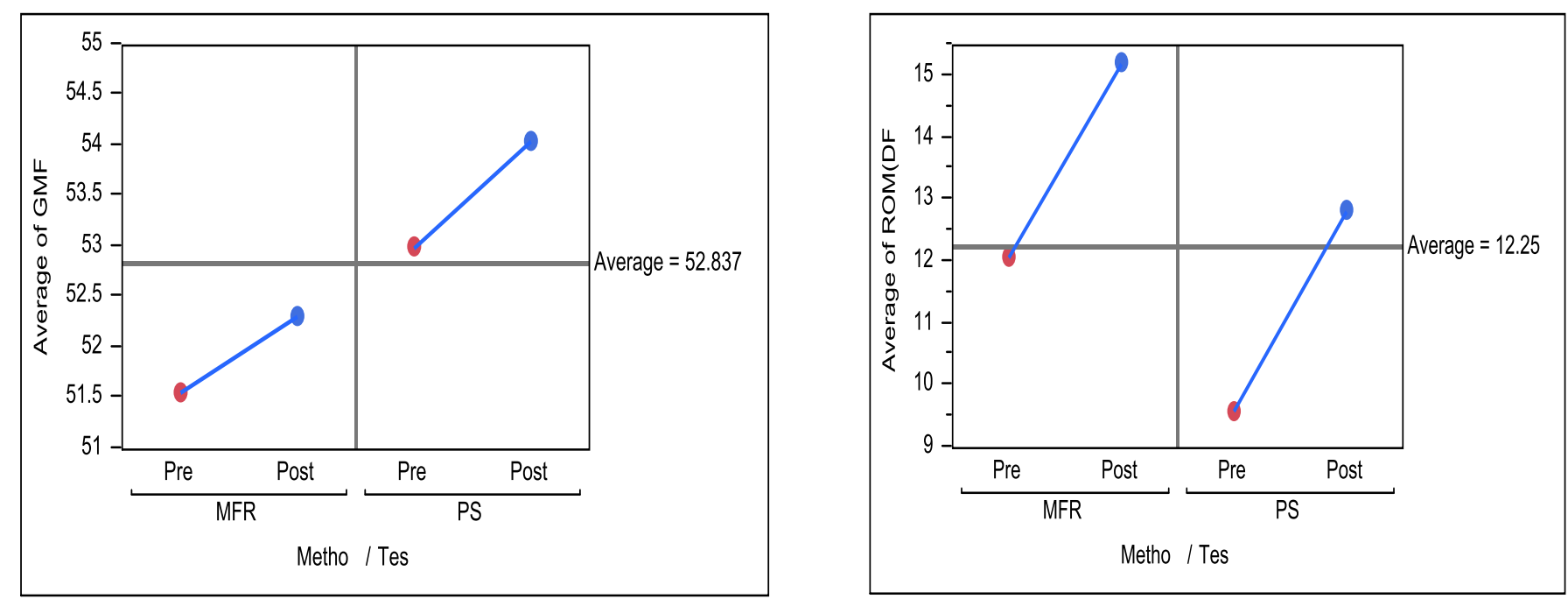


\section{Discussion}

Children with cerebral palsy often demonstrate spasticity as a primary clinical manifestation. The spasticity of lower extremity muscles makes the child non ambulatory. So, in order to address the disability caused due to spasticity various modes of treatment techniques are adopted. The present study is done to find the effectiveness of myofascial release techniques over conventional passive stretching technique. During the course of the research study 95 children were treated. Group I consisting of 41children and Group II consisting of 54 children were treated with Myofascial release technique and Passive stretching respectively for a period of 12 weeks for each children. The finding show that there were significant difference in treatment with both MFR and PS with $\mathrm{p}$ value $<0.001$. Moreover the effect of PS was found to be better than MFR with $\mathrm{p}$ value $<0.001$.

$\mathrm{Wu}$ Yn et al, 2011 in their study has clearly supported the result of this study stating that combined passive stretching and active movement gives significant increase in dorsiflexion range along with decrease in spasticity ${ }^{(2)}$

The finding of this study is also well supported by Tamis Pin et al which shows some evidence that manual stretching can increase ROM, reduce spasticity or improve walking efficiency ${ }^{(9)}$

But the results of a study by Owen M Katalinic, Lisa A, Harvey and Robert D.Herbert, 2010 contradicts the conclusion of our study stating that regular stretch does not produce clinically important changes in neurological disorders . ${ }^{(10)}$

Riley DA et al in 2012 had also given a positive remark by describing that passive stretch reduces muscle stiffness and may also induce addition of sarcomere size. ${ }^{(11)}$

\section{Conclusion}

On the basis of results of Pre Post GMFM and ROM (DF) measure, significant difference were found in case of MFR and PS $(\mathrm{p}<0.001)$ showing efficacy of intervention of both, however, on the basis of differentials increase in GMFM and
$\mathrm{ROM}(\mathrm{DF})$, passive stretching was found to be better than that of MFR $(\mathrm{p}<0.001)$ in the treatment of plantar flexors spasticity in children with Cerebral palsy. Further, analysis of MAS also found likelihood of superiority of same in case of MAS.

\section{References}

1. Jacob VC, Biju H, Sarma A, Lohia M, D’Souza M, Shetty A,Jani M. Neurorehabilitation - A Multidisciplinary Approach. 2012.Chapter 3, 142-145.

2. Wu YN, Hwang M, Ren Y, Gaebler-Spira D, Zhang LQ.Combined passive stretching and active movement rehabilitation of lower-limb impairments in children with cerebral palsy using a portable robot. Neurorehabil nerve repair. $2011 ; 25(4): 378-85$.

3. Fowles JR, Sale DG, MacDougall JD.Reduced strength after passive stretch of the human plantarflexors. J AppliPhysiol. 2000;89(3):1179-88.

4. Umpherd DA. Neurological Rehabilittion. $4^{\text {th }}$ ed , Chapter 33, 980-981

5. Manheim CJ. The Myofascial Release Manual. $4^{\text {th }}$, Section I, 8- 12

6. Armitage P, Berry G. Statistical Methods in Medical Research. $3^{\text {rd }}$ ed. Oxford: Blackwell Scientific Publications, 1994. 265, 430-437.

7. Petrie A, Paul W. Statistics for Veterinary and Animal Science. Blackwell Publishing Ltd. UK 2006.

8. Tukey J. "A problem of multiple comparisons," Dittoed manuscript of 396 pages, Princeton University 1953.

9. Pin T, Dyke P, Chan M. The effectiveness of passive stretching in children with cerebral palsy. Developmental medicine and child neurology.2006;48:855-862.

10. Katalinic OM, Harvey LA, Herbert RD. Effectiveness of Stretch for the Treatment and Prevention of Contractures in People With Neurological Conditions: A 
Systematic Review. Sydney, New South Wales, Australia; 1.harvey@usyd.edu.au.

11. Riley DA, Van Dyke JM.The effects of active and passive stretching on muscle length. Phys Med RehabilClin N Am.2012;23(1):51-7 